\title{
Flame-retardant Properties of Particleboard Made from Coconut Fibre Using Modified Potato Starch as a Binder
}

\author{
Amina Adedoja Owodunni, ${ }^{1}$ Rokiah Hashim, ${ }^{1 *}$ Owolabi Folahan Abdulwahab Taiwo, ${ }^{1,2}$ \\ Mohd Hazwan Hussin, ${ }^{3}$ Mohamad Haafiz Mohamad Kassim, ${ }^{1}$ Yazmin Bustami, ${ }^{4}$ \\ Othman Sulaiman, ${ }^{1}$ Mohd Hazim Mohamad Amini ${ }^{5}$ and Salim Hiziroglu ${ }^{6}$ \\ ${ }^{1}$ Division of Bioresource Technology, School of Industrial Technology, \\ Universiti Sains Malaysia, 11800 USM Pulau Pinang, Malaysia \\ ${ }^{2}$ Pulp and Paper Division, Federal Institute of Industrial Research Oshodi, \\ 100261 Lagos, Nigeria \\ ${ }^{3}$ School of Chemical Sciences, Universiti Sains Malaysia, \\ 11800 USM Pulau Pinang, Malaysia \\ ${ }^{4}$ School of Biological Sciences, Universiti Sains Malaysia, \\ 11800 USM Pulau Pinang, Malaysia \\ ${ }^{5}$ Faculty of Engineering and Technology, Universiti Malaysia Kelantan, \\ 16100 Kelantan, Malaysia
}

${ }^{6}$ Department of Natural Resource Ecology and Management, Oklahoma State University, Stillwater, OK74078-6013, United States

*Corresponding author: hrokiah@usm.my, hrokiah@gmail.com

Published online: 25 November 2020

To cite this article: Owodunni, A. A. et al. (2020). Flame-retardant properties of particleboard made from coconut fibre using modified potato starch as a binder. J. Phys. Sci., 31(3), 129-143. https://doi.org/10.21315/jps2020.31.3.10

To link to this article: https://doi.org/10.21315/jps2020.31.3.10

\begin{abstract}
This study seeks to evaluate the flame-retardant characteristics of experimental particleboard manufactured from coconut fibre using modified potato starch as a green binder. The coconut fibre was used as a replacement for the wood as a raw material in particleboard production. The adhesives used in the process were made by modifying potato starch with citric acid and glutardialdehyde. No flame-retardant additive was added during the processing, and this was done to evaluate the flame-retardant potential of the experimental coconut fibre-based particleboards. The limited oxygen index (LOI) test, the bomb calorimetry, the differential scanning calorimetry (DSC) and the dynamic mechanical analysis (DMA) were used to evaluate the thermal properties and flame retardancy rate of such particleboards. The result of the DMA showed that the coconut fibre-based particleboards had good storage modulus with heat. The bomb calorimeter and LOI results also supported the flame-retardant performance of the panels.
\end{abstract}


Based on the evaluations, it could be prescribed that the coconut fibre particleboard made with citric acid modified potato starch (CAMPS) exhibited the best flame-retardant properties.

Keywords: Flame retardant, coconut fibre-based particleboard, bomb calorimeter, DMA, LOI

\section{INTRODUCTION}

Particleboard is a wood composite product made by applying heat (increased temperature) and pressure on the wood particles (or lignocellulosic materials) bonded with the aid of an adhesive. The wood particles as raw material and the adhesive are mixed homogenously. The particle-mix is then pressed to form a sheet or a panel. In recent times, due to the environmental factors (deforestation) and sustainability goals in the particleboard industry, the search for potential alternatives that will replace the wood materials during the production process has become a necessity. Materials that are rich in lignin and cellulose (lignocellulosic materials), consisting of agricultural fibres and other non-wood plant fibres, undergo extensive research and development to achieve their optimum use. Various agricultural materials have been studied for their use in particleboard manufacturing include rice straw and coconut fibre, rape straw, corn stalks, coconut husks, oil palm trunk (OPT), sunflower bark and flax shives, banana and coconut fibre. ${ }^{1-7}$

Globally, the coconut tree and its products are extensively used in human activities. The coconut is processed for its milk, meat, water and oil. A major by-product generated from the coconut during its processing is the coconut husk which consists of the coconut fibre and the pith. The characteristics of the coconut fibre which have promoted its international acceptance as a raw material in furniture industries are not limited to its economical, renewable, long-lasting, durability, resistivity to thermal conductivity and ductile properties. ${ }^{8}$ Its potential to be used as an alternative to the wood particles in particleboard production stems from its high lignin content of about $59.4 \%-62.0 \%$, and alpha-cellulose content of $43.4 \%-$ $46.1 \%$. Although few studies have been done on producing particleboards using coconut fibres, the boards have been proven to enhance mechanical, physical and thermal properties. ${ }^{9}$

Synthetic adhesives based on formaldehyde such as urea-formaldehyde (UF), melamine urea-formaldehyde and phenol-formaldehyde (PF) have been commonly used as the binder in particleboard production. ${ }^{10} \mathrm{UF}$ and PF are the widely used synthetic adhesives for wood product processing. The use of PF resin produces panels with good mechanical strength and excellent water-resistant properties. 
However, they undergo hydrolysis resulting in high formaldehyde emission that endangers human health. ${ }^{11}$ To put an end to this challenge, numerous studies have been done on the use of starch to produce organic adhesive that will be free of formaldehyde, and meet up or surpass the advantageous qualities of the synthetic adhesives.

Starch-based wood adhesives are one of the natural environmentally friendly adhesives used in particleboard making; others include protein and lignin. Starch is a natural polymer (polysaccharide) obtained from the seeds, leaves and roots of plants such as corn, potato, rice, wheat, cassava and sago. ${ }^{12}$ The adhesives have the advantages of renewability, biodegradability, better adhesion and economical. The limitation of using of starch-based adhesives in particleboard has led to the current research works. Treatments, modifications and crosslinking of the starch are being studied to improve their physical, mechanical and thermal properties as they have been reported to have poor dimensional stability. ${ }^{13,14}$

The addition of citric acid to the starch in producing bamboo particleboards indicated the improvement of the physical and mechanical properties of the particleboard. ${ }^{15}$ In the fabrication of wood-composite, applying glutardialdehyde-modified oil palm starch (OPSMG) as adhesive by Amini et al., the mechanical, physical and thermal analyses were carried out to analyse the properties of the particleboards produced using the OPSMG as adhesive. ${ }^{16}$ The results obtained determined that the modified starch can be used as an environmental-friendly adhesive.

The application of particleboard as a flame-retardant material has been identified, researched and developed on in various studies. ${ }^{5,17-19}$ Compared to other types of the wood board which are not limited to plywood, fibreboards and solid woods, particleboard has numerous advantages such as being cost-effective, lightweight, and exhibit good strength and stiffness. ${ }^{20}$ However, it has a limit when used as a construction material because of its flammability. Wood materials have been reported to have low thermal stability which is a disadvantage when used as indoor construction materials. ${ }^{17}$ Flame-retardant materials obstruct and interrupt the rate of fire dispersal by altering the chemical reactions in the flame and forming a protective layer on the material's exterior; while some decompose the polymers in the solid stage of combustion and causes it to melt and move away from the flame. As such, flame-retardant particleboards are vastly used as an interior lining, floors, fixtures fittings and furniture frames. ${ }^{21}$

In the research on flame-retardancy, studies have been done involving the addition of flame-retardant agents. Some of these additives are inorganic which includes aluminium hydroxide, magnesium hydroxide, red phosphorus, ammonium polyphosphate, diammonium phosphate, boric acid, borax, zinc borate, aluminium 
trihydrate, monoammonium phosphate and ammonium bromide, while others organically produced are not limited to organophosphorus, organohalogen, organonitrogen organochlorine and intumescent flame retardants. ${ }^{5}$ Some of the chemicals used are toxic, and their toxins have been reported to cause melanoma, linked to leukaemia and has a contribution to cancer, as well as adding more to the cost of particleboard production or purchase. ${ }^{22}$

Thus, this research aims to study the flame-retardant property of experimental coconut fibre particleboard produced with modified potato starch as the binder.

\section{EXPERIMENTAL}

\subsection{Methods}

The coconut fibres were obtained from a mill in Sungai Besar, Selangor, Malaysia. The moisture content of the fibres was reduced by air-drying and was further ovendried to $7 \%$ moisture content. The potato starch, citric acid and glutardialdehyde were of analytical grade and were purchased from Sigma-Aldrich, R\&M Chemicals and Merck chemical company, respectively.

\subsection{Adhesives Preparation}

The native potato starch (NPS) was prepared by mixing the powder with distilled water to form a slurry, and the mixture was stirred at room temperature for $30 \mathrm{~min}$ and used as an adhesive in the particleboard production. ${ }^{23}$ In preparing the citric acid modified potato starch (CAMPS), the method used by Widyorini was slightly altered, the citric acid and potato starch were dissolved in hot distilled water of $70^{\circ} \mathrm{C} \pm 2^{\circ} \mathrm{C}$ in temperature. The mixture ratios of citric acid/starch were set at 75:25 (w/w), which was the optimum mixture ratio that gave the best particleboard properties. ${ }^{15}$ Glutardialdehyde modified potato starch (GMPS) was prepared by slightly altering the method described by Amini, the potato starch in powder form was modified with glutardialdehyde in liquid form in a ratio of 1:2 (w/w). The powder was mixed with distilled water at a temperature of $30^{\circ} \mathrm{C}$ and stirred thoroughly, it was then heated up to a temperature of about $50^{\circ} \mathrm{C}$ before the addition of glutardialdehyde. The mixture was continuously stirred and further heated up to $60^{\circ} \mathrm{C}$ before cooling and using as an adhesive..$^{16}$

\subsection{Particleboard Manufacturing}

Based on the oven-dry weight, $15 \%$ adhesive content was used and mixed with the fibres. The adhesives and coconut fibre mix were manually mixed in a deep 
bowl for $30 \mathrm{~min}$. The particle mix was then formed into a single layer mat with the aid of a mould with dimension of $20.5 \mathrm{~cm} \times 20.5 \mathrm{~cm} \times 0.5 \mathrm{~cm}$. It was then manually cold-pressed for $3 \mathrm{~min}$ before it was further hot-pressed at a temperature of $145^{\circ} \mathrm{C}$ and a pressure of $14 \mathrm{MPa}$ for $15 \mathrm{~min}$. A steel rod was used to achieve a constant thickness targeted at $0.5 \mathrm{~cm}$, and a target density of $0.80 \mathrm{~g} \mathrm{~cm}^{-3} \cdot{ }^{14}$ The panel samples were conditioned for $24 \mathrm{~h}$ to completely cool before trimming, and they were cut into the prescribed sizes for the various tests done.

\subsection{Limited Oxygen Index Test of the Samples}

The limited oxygen index (LOI) test was used to evaluate the flammability of the experimental panel samples. This study was done to detect the least oxygen concentration for full flaming incineration. The samples used in this evaluation were cut to a measurement of $8 \mathrm{~cm} \times 1 \mathrm{~cm}$ with 10 replicates for each sample. Fire Testing Technology LOI instrument was used to conduct this analysis in accordance with the ISO-4589 method. ${ }^{5}$ As shown in Figure 1, the prepared samples were placed and screwed with the holder in the centre of the glass column and was burned in a nitrogen $\left(\mathrm{N}_{2}\right)$ and oxygen $\left(\mathrm{O}_{2}\right)$ atmosphere and the LOI of the samples was analysed. ${ }^{24}$
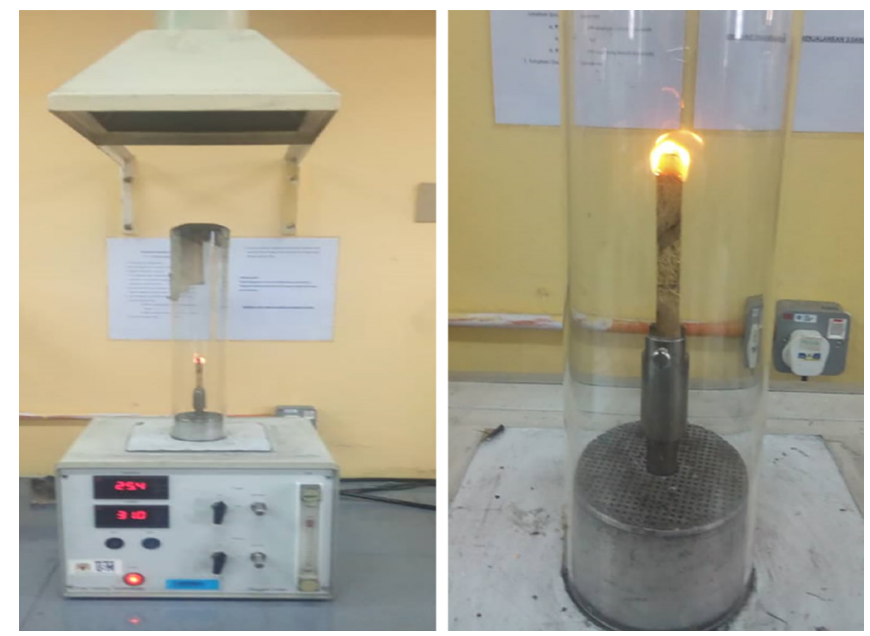

Figure 1: LOI experimental set-up.

\subsection{Gross Heat of Combustion Test}

To measure the gross heat $(\mathrm{GH})$ of combustion, the bomb calorimeter equipment was used. The analysis was done to confirm the heat capacity of the coconut fibrebased particleboards produced. The Parr 6200 Bomb calorimeter was used in 
accordance to the ISO $1716 .{ }^{25}$ The metal bucket where the specimen will be placed was filled with water, and the bomb was steadily charged with oxygen to $3 \mathrm{MPa}$ at ambient temperature as seen in Figure 2. Between $0.5 \mathrm{~g}$ and $1.0 \mathrm{~g}$ of the powdered samples was weighed and filled in the cylindrical crucible. The specimen was linked to the fused wire for combustion to take place. ${ }^{26}$
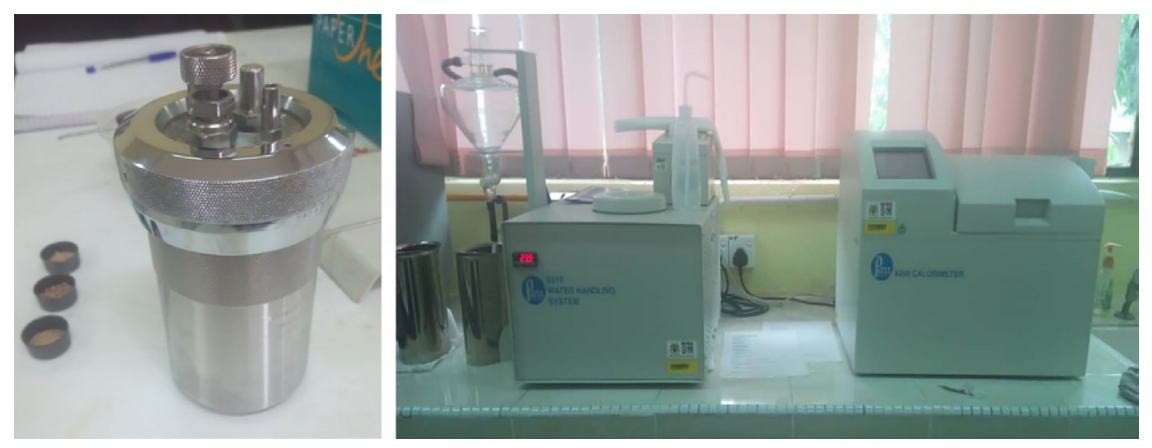

Figure 2: Bomb calorimeter experimental set-up.

\subsection{Dynamic Mechanical Analysis}

The dynamic mechanical analysis (DMA) was performed under a three-point cantilever mode using a Universal Q800.0 TA Instrument as shown in Figure 3. The dimensions of the specimens were $5 \mathrm{~cm} \times 1.25 \mathrm{~cm} \times 0.35 \mathrm{~cm}$. The specimens were scanned over a temperature range of $-20^{\circ} \mathrm{C}$ to $120^{\circ} \mathrm{C}$. The frequency of oscillation was fixed at $10 \mathrm{~Hz}$ and ramped at $5^{\circ} \mathrm{C} \mathrm{min}^{-1}$ to $120^{\circ} \mathrm{C}$. Storage modulus and mechanical loss factor $\left(\tan \delta\right.$ ) were recorded and plotted against temperature. ${ }^{27}$

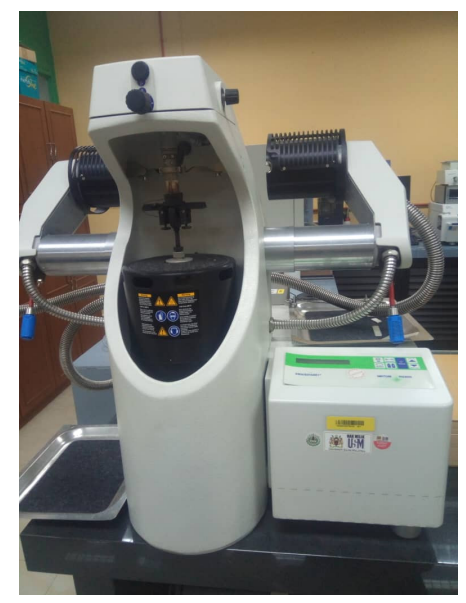

Figure 3: DMA experimental set-up. 


\subsection{Differential Scanning Calorimetry}

Differential scanning calorimetry (DSC) analyses of boards were performed in a DSC instrument (DSC 6 model Q200) as shown in Figure 4. Ground sample within 5-10 mg was weighed into the aluminium pan and covered with the lid. The powdered sample was placed in the DSC heating pan to begin the evaluation. The sample was heated within the range of $-15^{\circ} \mathrm{C}$ to $280^{\circ} \mathrm{C}$ with a heating rate of $10^{\circ} \mathrm{C}$ $\min ^{-1}$ under a nitrogen atmosphere. ${ }^{28}$

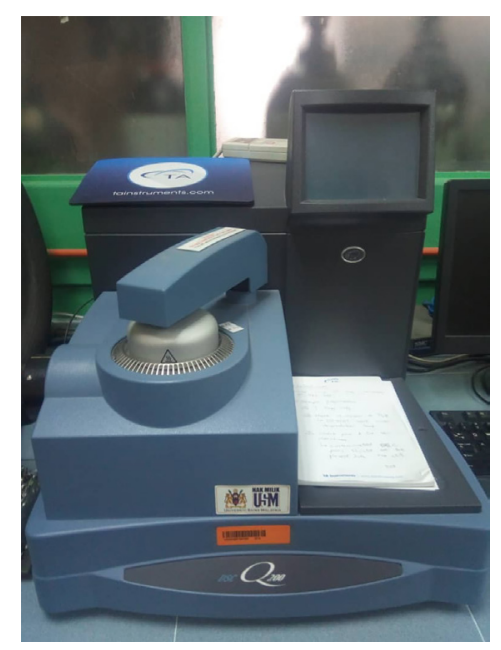

Figure 4: DSC analysis experimental set-up.

\section{RESULTS}

\subsection{LOI Test}

The LOI test is specifically a method used to evaluate the lowest concentration of oxygen in a mixture with nitrogen that will be enough to aid combustion, and is expressed in volume percentage (\%). It is generally used to determine the average flammability of polymeric substances. It has been reported that the higher the LOI values of the coconut fibre-based particleboard, the more flame-retardant it is (which means lower flammability). ${ }^{29}$ Materials that give a resulting LOI value greater than $21 \%$ is said to be non-flammable, due to the $21 \%$ of oxygen already present in the air. There are four categories for flammable materials, namely (1) LOI $<20.95$, (2) $20.95<$ LOI $<28.0$, (3) $28.0<$ LOI $<100$, which are categorised as self-extinguishing materials; and (4) LOI $>100$, these materials are categorised as intrinsically non-flammable. ${ }^{29}$ Therefore, it can be concluded that 
materials with LOI value above $28 \%$ should be considered as a self-extinguishing material that will stop burning upon the removal of the fire or the source of ignition.

The results from this study in Table 1 represent the LOI values or the coconut fibre-based particleboards. The table shows that the experimental panels are selfextinguishing materials and they do not propagate burning when its source is removed. Comparing the LOI values of the coconut fibre particleboards produced using the different adhesives, there is little or no effects of the adhesive compositions on the flammability of the samples. It could be concluded that the coconut fibre is the principal component that influenced the flame-retardant property in the particleboard samples, and this could be attributed to the belief that lignocellulosic fibres with low alpha-cellulose and high lignin content have lower flammability compared to those with fibres with higher cellulose such as cotton. ${ }^{30}$

Table 1: LOI for all the particleboards produced.

\begin{tabular}{lc}
\hline Particleboard type & LOI $(\%)$ \\
\hline NPS & $31.1(0.11)$ \\
CAMPS & $31.3(0.16)$ \\
GMPS & $29.3(0.11)$ \\
\hline
\end{tabular}

Note: The value in parenthesis is the standard deviation

The results of the combustion of all the types of particleboards have LOI indexes ranging from $29.3 \%$ to $31.3 \%$. They are unaffected by severe flames and after it has been ignited, they do not crush. The flammability of the particleboard sample is affected by factors such as the ease of ignition (how quickly the sample ignites), the flame spread (how quickly fire spreads across a polymer surface), fire endurance (how quickly fire penetrates the sample), the rate of heat released, and the ease of flame extinction..$^{30}$ The difference in the LOI values of the particleboards could also be attributed to their different adhesives used to bind them while burning some polymers emit blanketing gases that suppress burning.

In studying the properties of particleboard made from OPT with the addition of magnesium oxide as flame retardant by Selamat et al., the LOI for the OPT particleboards produced were evaluated, with the highest LOI value of $30.81 \%$ obtained for the particleboard made with $20 \%$ magnesium oxide flame retardant additive. ${ }^{5}$ The result obtained in this study of coconut fibre particleboards is comparable to that of the OPT particleboard. To further increase the LOI, flame retardant additives could be added to the process as it is believed that a small amount of additives could significantly improve the flame-retardant properties of the particleboard. ${ }^{18}$ 


\subsection{GH of Combustion}

The combustibility of the experimental particleboard samples is displayed by the $\mathrm{GH}$ of combustion and was tested with the aid of a bomb calorimeter. One of the important parameters of evaluating a flame-retardant material is the $\mathrm{GH}$ of combustion of the reaction between the particleboard samples and oxygen based on the temperature variation of the water. The GH is the quantity of energy released when a unit mass of fuel is burned in a constant volume enclosure with the products being gaseous, other than water that is condensed to the liquid state. ${ }^{26}$

Table 2: GH of combustion.

\begin{tabular}{lc}
\hline Particleboard type & $\mathrm{GH}\left(\mathrm{MJ} \mathrm{kg}^{-1}\right)$ \\
\hline NPS & $17.04(0.29)$ \\
CAMPS & $19.26(0.38)$ \\
GMPS & $14.26(0.22)$ \\
\hline \multicolumn{2}{l}{ Note: The value in parenthesis is the standard deviation }
\end{tabular}

All the experimental panels were produced without the inclusion of a fire-resistant additive. Table 2 illustrates the evaluation obtained from the analysis. The panel sample made with CAMPS used as an adhesive had the highest GH value of 19.26 MJ kg-1 which could be attributed to the high molecular weight of citric acid of $192.124 \mathrm{~g} \mathrm{~mol}^{-1}$. Meanwhile, the samples produced with potato starch as a binder had a slightly reduced value of $17.04 \mathrm{MJ} \mathrm{kg}^{-1}$. However, the glutardialdehyde bonded panel samples produced a $14.26 \mathrm{MJ} \mathrm{kg}^{-1} \mathrm{GH}$ value. The lower calorific value of the GMPS bonded samples could be attributed to the non-flammability and non-combustible nature of the glutardialdehyde liquid. ${ }^{31}$

\subsection{DMA}

The loss factor $(\tan \delta)$ results in the time lag between the applied strain. Figures 5 and 6 show the results obtained from the DMA, giving the storage modulus and $\tan \delta$. The different particleboards showed different trends of loss factors as their temperatures increased. ${ }^{32}$

The value of the storage modulus represents the stiffness (strength) of the material. Particleboard samples bonded with GMPS have been shown to have the highest strength at $2275.63 \mathrm{MPa}$, while the samples bonded with pure potato starch had the lowest modulus at $1572.07 \mathrm{MPa}$. This can be attributed to the modification of starch with the glutardialdehyde that increased the surface area and interfacial bonding. The strength of the experimental panels bonded with CAMPS is higher when compared with the samples made with unmodified starch. 
The peak of the tan $\delta$ represents the glass transition temperatures, with the graph in Figure 6 showing a wider peak, which is a typical characteristic of amorphous substances. Also, the graph of the tan $\delta$ shows a lower peak, signifying good miscibility between the material mix. GMPS bonded samples graph has the lowest and widest $\tan \delta$ peak, which corroborates its mechanical strength as shown in the graph representing the storage modulus.

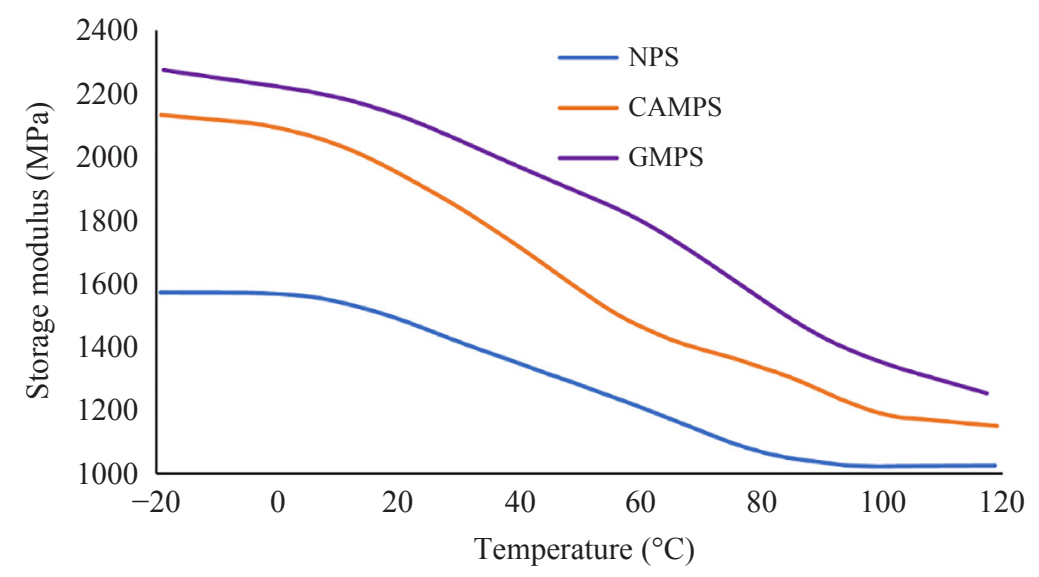

Figure 5: Storage modulus curves of particleboards from the three adhesives.

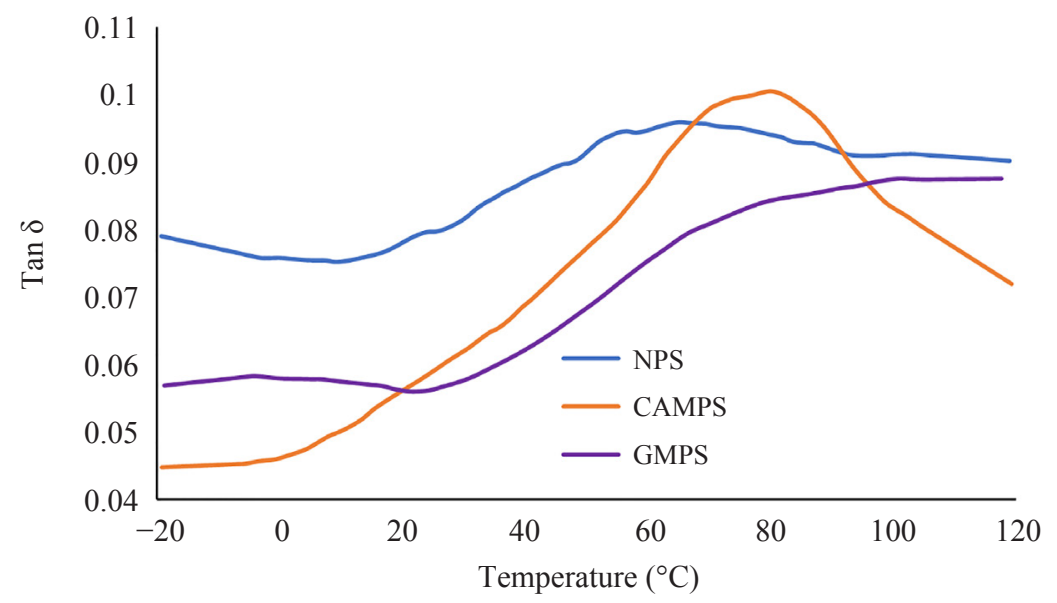

Figure 6: Loss factor $(\tan \delta)$ vs. temperature curves of particleboards made from the different adhesives. 
The high value of the storage modulus of the modified adhesives can be attributed to possible chemical reactions between the starch, the modifiers and the coconut fibre particles. These reactions resulted in stronger bonds produced between the materials. Also, the unmodified starch low storage modulus shows low bond strength between the particleboard materials. ${ }^{33}$

\subsection{DSC Test}

The particleboard samples produced with the starch adhesives were analysed for its DSC. This analysis is evaluated to obtain information on the thermal changes without the involvement in the weight of the sample. ${ }^{34}$ The results of the DSC evaluation are depicted in Figure 7. From the plots, the onset temperature signifies the beginning of melting of the board samples, and the sample bonded with NPS adhesive had the highest onset temperature of $34.71^{\circ} \mathrm{C}$, while the lowest onset temperature of $24.83^{\circ} \mathrm{C}$ was obtained for the CAMPS samples. The glass transition temperature for the CAMPS sample was depicted to be the highest, reaching a temperature of $140.37^{\circ} \mathrm{C}$. After this temperature, the sample materials start to lose their mechanical properties and degrade gradually. The melting point is the temperature where the particleboard sample starts to decompose totally, and the NPS board sample gave the highest melting point of $256.73^{\circ} \mathrm{C}$, followed closely by the GMPS board sample with a melting temperature of $248.79^{\circ} \mathrm{C}$. CAMPS board samples gave the lowest temperature of $194.84^{\circ} \mathrm{C}$.

The temperature results of the glass transition obtained from both the DMA and DSC can be compared. The results of the DSC analysis corroborate that of the DMA. The glass transition temperature (Tg) measurement is visible at the peak of loss factor $(\tan \delta$ ) curves of DMA analysis. The Tg obtained from the DMA is more accurate compared to that of the DSC according to previous literature. ${ }^{35}$ The Tg from the tan $\delta$ curve of the DMA studies showed broader peaks compared to that of the DSC result. However, similar trend was obtained from the graphs of DMA and DSC. The results showed that CAMPS have the highest Tg which corroborate the high storage modulus value in the DMA. The increase in storage modulus is a result of the crystallisation of the material, and further decreases as the melted material change into a rather low viscous liquid. 
(a)

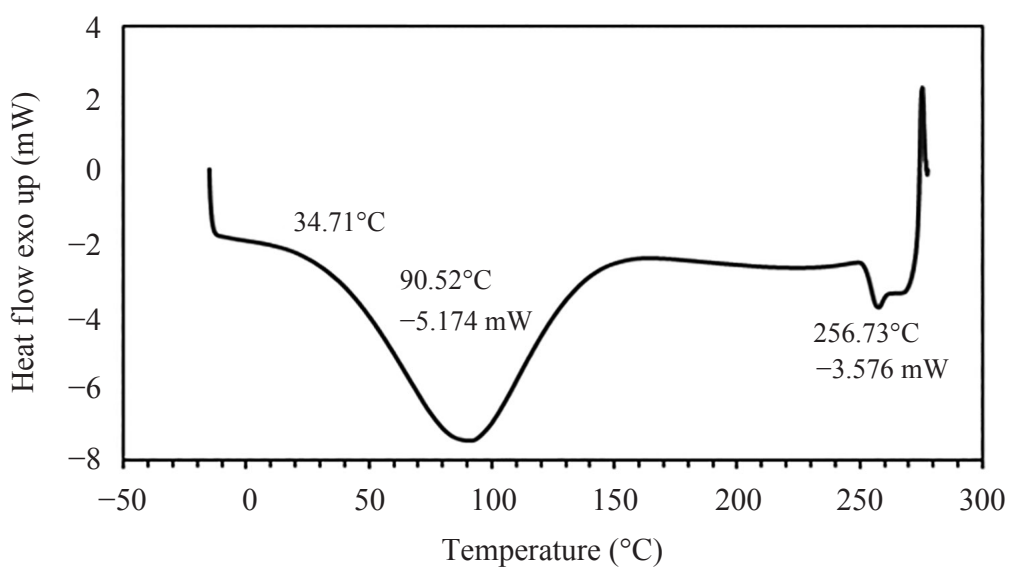

(b)

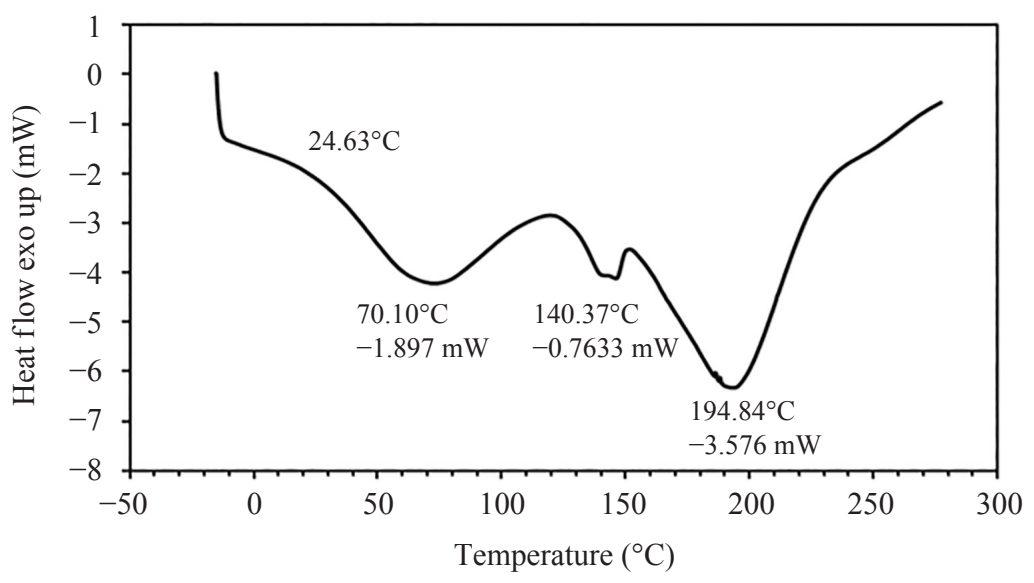

(c)

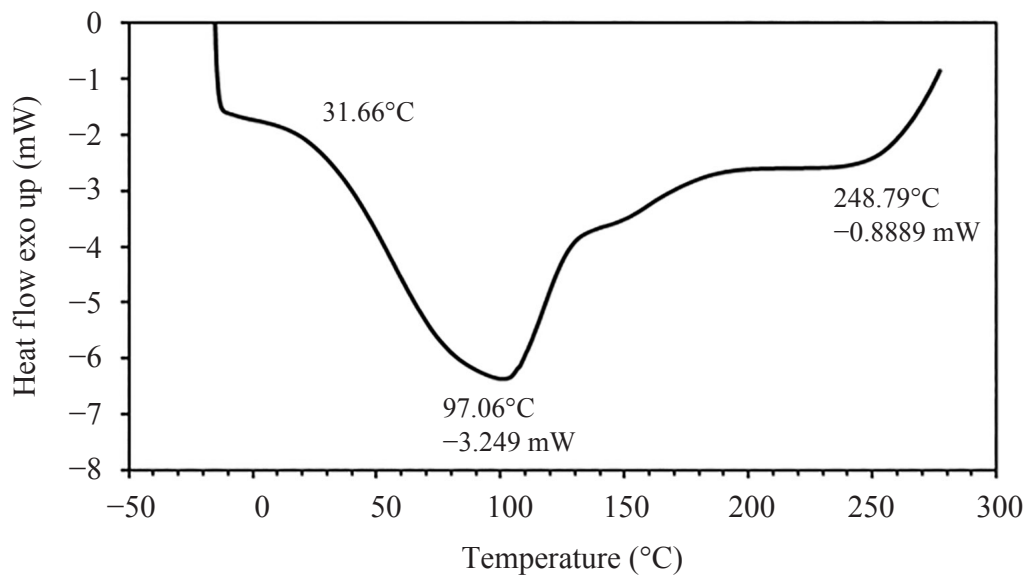

Figure 7: DSC thermograms of particleboard bonded with (a) NPS, (b) CAMPS, and (c) GMPS adhesives. 


\section{CONCLUSION}

Coconut fibre-based particleboard was produced with a highly rich lignocellulosic material. In this study, its potential as a flame-retardant material was tested using the LOI test. The DSC and the DMA were used to determine the stiffness and damping characteristics of the experimental panels by studying their viscoelastic properties. From the bomb calorimetry tests, the GH of combustion of the particleboard samples was obtained and the particleboard produced with citric acid-modified starch had the highest value. Similar performance was also noted for the results obtained from the LOI test. It can be concluded that particleboards produced using coconut fibre has the potential to be applied as a flame-retardant material in furniture making, building and construction industries. However, future research is encouraged to be done by studying the effects of adding various flameretardant agents such as sodium aluminate, diammonium phosphate, phosphoric acid, monoammonium phosphate, magnesium oxide and aluminium trihydrate, in the production process, to further boost the flame retardancy.

\section{ACKNOWLEDGEMENTS}

The authors acknowledge Universiti Sains Malaysia (USM) for the research finance and support through Research University Grant (1001/PTEKIND/8014083).

\section{REFERENCES}

1. Zhang, L. \& Hu, Y. (2014). Novel lignocellulosic hybrid particleboard composites made from rice straws and coir fibers. Mater. Des., 55, 19-26. https://doi. org/10.1016/j.matdes.2013.09.066

2. Cosereanu, C. \& Cerbu, C. (2019). Morphology, physical, and mechanical properties of particleboard made from rape straw and wood particles glued with urea-formaldehyde resin. BioResour., 14(2), 2903-2918.

3. Prasetiyo, K. W. et al. (2019). Physical-mechanical properties and bonding mechanism of corn stalks particleboard with citric acid adhesive. J. Ilmu Teknol. Kayu Trop., 16(2), 132-141.

4. Junior, C. P. A. et al. (2018). Binderless fiberboards made from unripe coconut husks. Waste Biomass Valor., 9(11), 2245-2254. https://doi.org/10.1007/s12649017-9979-9

5. Selamat, M. E. et al. (2018). Properties of particleboard made from oil palm trunks added magnesium oxide as fire retardant. J. Phys. Sci., 29(1), 59-75. https://doi.org/10.21315/jps2018.29.1.5

6. Mahieu, A. Alix, S. \& Leblanc, N. (2019). Properties of particleboards made of agricultural by-products with a classical binder or self-bound. Ind. Crops Prod., 130(April), 371-379. https://doi.org/10.1016/j.indcrop.2018.12.094 
7. Jústiz-Smith, N. G., Virgo, G. J. \& Buchanan, V. E. (2008). Potential of Jamaican banana, coconut coir and bagasse fibres as composite materials. Mater. Char., 59(9), 1273-1278. https://doi.org/10.1016/j.matchar.2007.10.011

8. Verma, D. et al. (2013). Coir fibre reinforcement and application in polymer composites. J. Mater. Environ. Sci., 4(2), 263-276.

9. Owodunni, A. A. et al. (2020). Properties of green particleboard manufactured from coconut fiber using a potato starch based adhesive. BioResour., 15(2), 2279-2292.

10. Kariuki, S. W. et al. (2019). Formaldehyde use and alternative biobased binders for particleboard formulation: A review. J. Chem. https://doi.org/10 $.1155 / 2019 / 5256897$

11. Pizzi, A. \& Mittal, K. L. (2017). Handbook of adhesive technology (3rd ed.). Boca Raton: CRC Press.

12. Zhang, Y. et al. (2015). Preparation and properties of a starch-based wood adhesive with high bonding strength and water resistance. Carbohyd. Polym., 115, 32-37. https://doi.org/10.1016/j.carbpol.2014.08.063

13. Gadhave, R. V., Mahanwar, P. A. \& Gadekar, P. T. (2017). Starch-based adhesives for wood/wood composite bonding: Review. Open J. Polym. Chem., 7(2), 19-32. https://doi.org/10.4236/ojpchem.2017.72002

14. Lamaming, J. et al. (2020). Characterization of rubberwood particleboard made using carboxymethyl starch mixed with polyvinyl alcohol as adhesive. Comp. B Eng., 183, 107731. https://doi.org/10.1016/j.compositesb.2019.107731

15. Widyorini, R. et al. (2017). Effect of starch addition on properties of citric acidbonded particleboard made from bamboo. BioResour., 12(4), 8068-8077.

16. Amini, M. H. M., Hashim, R. \& Sulaiman, N. S. (2019). Formaldehyde-free wood composite fabricated using oil palm starch modified with glutardialdehyde as the binder. Int. J. Chem. Eng., 1-9. https://doi.org/10.1155/2019/5357890

17. Seo, H. J. et al. (2016). Enhancing the flame-retardant performance of woodbased materials using carbon-based materials. J. Therm. Anal. Calorimet., 123(3), 1935-1942. https://doi.org/10.1007/s10973-015-4553-9

18. Tang, Y. et al. (2008). A formaldehyde-free flame retardant wood particleboard system based on two-component polyurethane adhesive. J. Appl. Polym. Sci., 108(2), 1216-1222. https://doi.org/10.1002/app.27662

19. Hashim, R. et al. (2009). Physical and mechanical properties of flame retardant urea formaldehyde medium density fiberboard. J. Mater. Process. Technol., 209(2), 635-640. https://doi.org/10.1016/j.jmatprotec.2008.02.036

20. Amatosa, T. A. \& Loretero, M. E. (2020). Bamboo waste-based bio-composite substance: an application for low-cost construction materials. J. Technol., 4(1), 41-48. https://doi.org/10.35718/specta.v4i1.162

21. Godish, T. (2016). Indoor environmental quality. New York: CRC Press.

22. Stec, A. A. (2017). Fire toxicity: The elephant in the room? Fire Safe. J., 91, 79-90.

23. Sulaiman, N. S. et al. (2018). Partial replacement of urea-formaldehyde with modified oil palm starch based adhesive to fabricate particleboard. Int. J. Adhes. Adhes., 84, 1-8. https://doi.org/10.1016/j.ijadhadh.2018.02.002 
24. Keskin, H., Kucuktuvek, M. \& Guru, M. (2015). The potential of poppy (Papaver somniferum Linnaeus) husk for manufacturing wood-based particleboards. Constr. Build. Mater., 95, 224-231. https://doi.org/10.1016/j.conbuildmat.2015 .07 .160

25. International Standard Organization (ISO). (2018). Reaction to fire tests for building products: Determination of gross calorific value. Geneva: ISO.

26. Khalili, P. et al. (2017). Synergistic of ammonium polyphosphate and alumina trihydrate as fire retardants for natural fiber reinforced epoxy composite. Comp. B Eng., 114, 101-110. https://doi.org/10.1016/j.compositesb.2017.01.049

27. Tayfun, U., Dogan, M. \& Bayramli, E. (2016). Effect of surface modification of rice straw on mechanical and flow properties of TPU-based green composites. Polym. Comp., 37(5), 1596-1602. https://doi.org/10.1002/pc.23331

28. Sulaiman, N. S. et al. (2012). Evaluation of the properties of particleboard made using oil palm starch modified with epichlorohydrin. BioResour., 8(1), 283-301.

29. Kererekes, Z. et al. (2018). Standard fire testing of chimney linings from composite materials. J. Build. Eng., 19, 530-538. https://doi.org/10.1016/j.jobe.2018.05.030

30. Mohamed, A. L. \& Hassabo, A. G. (2015). Flame retardant of cellulosic materials and their composites. London: Springer.

31. Sayers, E. W. et al. (2020). Database resources of the national center for biotechnology information. Nucl. Acids Res., 48(1), 9-16. https://doi.org/10 .1093/nar/gkz899

32. Battegazzore, D. et al. (2017). Layer by layer-functionalized rice husk particles: A novel and sustainable solution for particleboard production. Mater. Tod. Comm., 13, 92-101. https://doi.org/10.1016/j.mtcomm.2017.09.006

33. Zhang, Y. et al. (2011). Straw based particleboard bonded with composite adhesives. BioResour., 6(1), 464-476.

34. Charsley, E. et al. (2019). Principles of thermal analysis and calorimetry (2nd ed). Cambridge: Royal Society of Chemistry.

35. Yong, A. X. et al. (2017). Heating rate effects on thermal analysis measurement of $T_{g}$ in composite materials. Adv. Man. Polym. Comp. Sci., 3(2), 43-51. https://doi.org/10.1080/20550340.2017.1315908 